\title{
Atypical nummular headache or circumscribed migraine: The utility of pressure algometry
}

\author{
Johanna Barón $M D^{1}$, Cristina Rodríguez $M D^{1}$, Marina Ruiz $M D^{1}$, María Isabel Pedraza MD , Ángel Luis Guerrero MD¹, \\ Pascal Madeleine PhD², María Luz Cuadrado $\mathrm{PhD}^{3}$, César Fernández-de-las-Peñas PhD 4
}

\begin{abstract}
J Barón, C Rodríguez, M Ruiz, et al. Atypical nummular headache or circumscribed migraine: The utility of pressure algometry. Pain Res Manag 2015;20(2):60-62.

A peripheral mechanism has been proposed for nummular headache; however, there have been descriptions of atypical features resembling migraine. The authors describe a case in which algometry assessment facilitated the discrimination between atypical nummular headache and circumscribed migraine. A 21-year-old woman presented with a history of focal episodic pain in a circumscribed area on the left frontal region. The algometry study showed a unilateral and diffuse decrease of the pain pressure thresholds with frontal predominance, as has been proposed for migraine patients. This result led the authors to introduce a more specific preventive therapy with topiramate, with significant relief. In conclusion, cartographic investigation of pressure pain sensitivity is a simple tool that can help to differentiate between nummular headache and migraine. Further confirmatory investigations are needed.
\end{abstract}

Key Words: Algometry; Cartography; Migraine; Nummular headache; Pressure pain thresholds

Jummular headache (NH) was first described in 2002 by Pareja et 1 al (1). It was included in the research appendix of the International Classification of Headache Disorders, 2nd edition (ICHD-II), and has recently been moved to the main body of the ICHD-III beta, under the category of other primary headaches (2). NH is defined as a continuous or intermittent pain, commonly described as oppressive and felt exclusively in a rounded or elliptical area, typically $1 \mathrm{~cm}$ to $6 \mathrm{~cm}$ in diameter $(1,2)$. Its confinement to a well-circumscribed area, as well as symptoms and signs of sensory dysfunction into the affected area, such as tenderness, allodynia, paresthesia, hypoesthesia and trophic changes, suggest a peripheral mechanism. Pain in NH likely stems from epicranial tissues (3). Nevertheless, some patients show atypical features resembling a migraine pattern such as episodic pain, accompanying nausea, photophobia and phonophobia (4), pain triggering or aggravation with physical exercise (5), or temporal relation to menses (6).

We present a case in which pressure algometry assessment facilitated the differential diagnosis between $\mathrm{NH}$ and migraine, and led to the initiation of a more effective therapy.

\section{CASE PRESENTATION}

A 21-year-old woman was referred to a headache outpatient office due to a three-year history of focal episodic pain located in a circumscribed area on the left frontal scalp. The patient had no personal or family history of typical migraine. The painful area was round and measured $5 \mathrm{~cm}$ in diameter. The pain was described as oppressive and throbbing, with an intensity score of 7 of 10 on a visual analogue scale on which

\section{La céphalée nummulaire atypique ou la migraine circonscrite : l'utilité de l'algométrie à pression}

Un mécanisme périphérique a été proposé pour expliquer les céphalées nummulaires. Cependant, des caractéristiques atypiques peuvent évoquer la migraine. Les auteurs décrivent un cas où l'évaluation par algométrie a permis de mieux distinguer la céphalée nummulaire atypique de la migraine circonscrite. Une femme de 21 ans a consulté en raison d'antécédents de douleurs focales épisodiques dans une zone circonscrite de la région frontale gauche. L'étude d'algométrie a révélé une diminution unilatérale et diffuse des seuils de pression douloureuse à prédominance frontale, comme on le propose chez les patients migraineux. Ce résultat a incité les auteurs à adopter une thérapie préventive plus spécifique au topiramate, qui a beaucoup soulagé la patiente. Ainsi, l'examen cartographique de la sensibilité à la pression douloureuse est un outil simple qui peut contribuer à distinguer la céphalée nummulaire de la migraine. D’autres recherches de confirmation s'imposent.

$0=$ no pain and $10=$ the worst imaginable pain. Each attack lasted for approximately $1 \mathrm{~h}$ and was associated with phonophobia and photophobia; pain was also aggravated by physical activity and was constant in location. The patient described eight to 10 episodes/month and used acetaminophen with only partial relief; she did not identify any clear trigger or menstrual relationship. The neurological examination was unremarkable, with neither sensory symptoms nor trophic changes inside the painful area. No tenderness was identified on palpation of the left supraorbital nerve. Blood tests and magnetic resonance imaging were also normal.

According to the initial diagnosis of $\mathrm{NH}$, preventive treatment with $800 \mathrm{mg} /$ day of gabapentin was initiated, with no significant pain relief. Thus, the authors decided to perform a cartographic study of pressure pain sensitivity on the patient's scalp. The study procedure was conducted following previously published guidelines (7). The patient was headache free on the day of evaluation. Pain pressure thresholds (PPT) were measured on 21 points distributed over the scalp. The locations of and nomenclature for these points were based on standard position of international $10 / 20$ and $10 / 10$ systems for electroencephalogram recordings. Eight points on the right (Fp2, F4, F8, C4, T4, P4, T6 and O2), eight points on the left (Fp1, F3, F7, C3, T3, P3, T5 and O1) and five points along the midsagittal curve (Fpz, $\mathrm{Fz}, \mathrm{Cz}, \mathrm{Pz}$ and $\mathrm{Oz}$ ) were assessed. The centre of the symptomatic area (between Fp1 and F3) and a symmetrical contralateral point were also assessed in agreement with previous guidelines (7). Therefore, the patient had 23 matching points for PPT assessments (the 21 standardized points plus the symptomatic point and the nonsymptomatic

\footnotetext{
${ }^{1}$ Neurology Department, Hospital Clínico Universitario de Valladolid, Valladolid, Spain; ${ }^{2}$ Centre for Sensory-Motor Interaction, Department of Health Science and Technology, Aalborg University, Aalborg, Denmark; ${ }^{3}$ Neurology Department, Hospital Clinico San Carlos, Universidad Complutense de Madrid; ${ }^{4}$ Departamento de Fisioterapia, Terapia Ocupacional, Rehabilitación y Medicina Física, Universidad Rey Juan Carlos, Alcorcón, Madrid, Spain

Correspondence: Dr Ángel Luis Guerrero, Neurology Department, Hospital Clínico Universitario, Avda Ramón y Cajal 3 , 47005 Valladolid, Spain. Telephone 00-36-983470000, e-mail gueneurolgmail.com
} 
TABLE 1

Mean pressure pain thresholds over the scalp

\begin{tabular}{|c|c|}
\hline Localization & Mean pressure pain threshold, $\mathrm{kg} / \mathrm{cm}^{2}$ \\
\hline$\overline{F p Z}$ & 1.23 \\
\hline Fp1 & 1.10 \\
\hline $\mathrm{Fp} 2$ & 1.48 \\
\hline $\mathrm{FZ}$ & 1.93 \\
\hline F3 & 1.17 \\
\hline F4 & 1.50 \\
\hline F7 & 1.37 \\
\hline F8 & 1.55 \\
\hline$C Z$ & 1.53 \\
\hline C3 & 1.42 \\
\hline C4 & 1.43 \\
\hline T3 & 1.17 \\
\hline T4 & 1.22 \\
\hline PZ & 1.87 \\
\hline P3 & 1.43 \\
\hline P4 & 1.55 \\
\hline T5 & 1.68 \\
\hline T6 & 1.58 \\
\hline $\mathrm{OZ}$ & 1.53 \\
\hline 01 & 1.53 \\
\hline $\mathrm{O} 2$ & 1.75 \\
\hline Fp1-F3 (Painful point) & 1.23 \\
\hline Fp2-F4 (Contralateral point) & 1.88 \\
\hline
\end{tabular}

contralateral point). All of these points were marked using a marker pen by one of the coauthors over the scalp.

Subsequently, the PPT on each of the marked points was measured by a second assessor using a pressure algometer. This device is a $1 \mathrm{~cm}^{2}$ rubber disk attached to the pole of a pressure gauge, which displays pressure values in $\mathrm{kg} / \mathrm{cm}^{2}$. The patient indicated verbally to stop the pressure stimulation when the PPT was reached. PPT was defined as the minimal amount of pressure at which a sense of pressure changes to pain. Three consecutive measurements at intervals of $30 \mathrm{~s}$ were obtained for each point. The order of point assessment was randomized. The mean value of the three PPT measurements was computed for each point (Table 1). Using these data, appropriate software applications $(7,8)$ were used to construct a map of the spatial distribution of pressure pain sensitivity over the scalp (Figure 1).

\section{RESULTS}

In the topographical map, PPTs were identified to be diffusely decreased over the left hemicranium, with frontal predominance (Fp1: 1.10, F3: 1.17, F7: 1.37 and Fp1-F3 [pain point]: 1.23), resembling patterns previously described in migraine patients (8). The PTT values in these four points were compared with those located in the symmetrical contralateral scalp using a $t$ test. Measurements were significantly decreased over the left scalp $(1.21 \pm 0.11$ versus $1.6 \pm 0.18, \mathrm{P}=0.013)$.

Symptomatic therapy with almotriptan was then initiated, with significant relief of pain attacks. Preventive treatment with topiramate that was titrated to $100 \mathrm{mg} /$ day was also recommended; a significant reduction in pain attacks (two per month) and their intensity (5 of 10 on a visual analogue scale) was also achieved.

\section{DISCUSSION}

The present case fulfilled the diagnostic criteria of $\mathrm{NH}$ according to ICHD-III (2) because it was a circumscribed pain felt in a small area of the scalp $(5 \mathrm{~cm})$. It may also have been interpreted as a probable migraine without aura with atypical location and duration of pain attacks. From the first description of $\mathrm{NH}$ (1), the clinical spectrum of this entity has increased. Many patients experience continuous pain,

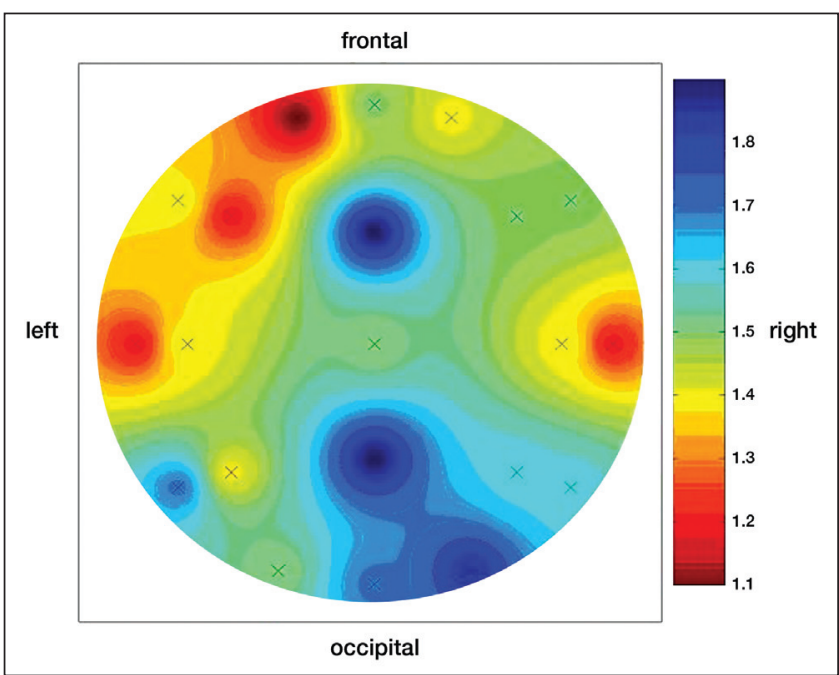

Figure 1) Map of the spatial distribution of pressure pain sensitivity

with or without exacerbations (9), while others have an intermittent pain with pain-free intervals, as occurred in the current case $(10,11)$.

Contrary to characteristics suggesting a peripheral origin of $\mathrm{NH}$, some data tend to support a central origin of $\mathrm{NH}$ in some patients, such as multifocal descriptions or pain reappearance in another area after removal of symptomatic NH scalp (4). On the other hand, the occurrence of migraine in a single location has been described, mainly around the eyes, or in the frontal or temporal scalp $(12,13)$.

According to the atypical characteristics in the current case, were we faced with an $\mathrm{NH}$ with central sensitization, or an atypical circumscribed migraine? We decided to begin with the first-line therapy choice for $\mathrm{NH}$ (gabapentin), which was ineffective; therefore, we decided to perform a cartographic study of pressure pain sensitivity. This easily performed technique demonstrated a diffusely decreased PPT over the left hemicranium with frontal predominance, as has been previously described in migraine (8), contrary to the strictly local decrease in PPT over the symptomatic area typical of $\mathrm{NH}$ (7). Strictly speaking, the duration of the pain attacks were too short for a migraine and, thus, the effect of almotriptan was not easily judged. Regardless, when standard antimigraine symptomatic and preventive therapies were added, significant improvement was achieved.

\section{CONCLUSION}

A clinical picture of episodic $\mathrm{NH}$ with atypical features may correspond to a 'nummular migraine', and may exhibit different therapy responsiveness. Pressure algometry is a simple technique that can help in the diagnosis of $\mathrm{NH}$ or migraine. Additional descriptions are needed to confirm this hypothesis.

DISCLOSURES: The authors have no conflicts of interest to declare. No financial support was required for this report.

\section{REFERENCES}

1. Pareja JA, Caminero AB, Serra J, et al. Nummular headache: A coin-shaped cephalalgia. Neurology 2002;58:1678-9.

2. Headache Classification Subcommittee of the International Headache Society. The International Classification of Headache Disorders, 3rd edition (beta version). Cephalalgia 2013;33:629-808.

3. Pareja JA, Pareja J, Yanguela J. Nummular headache, trochleitis, supraorbital neuralgia, and other epicranial headaches and neuralgias: The epicranias. J Headache Pain 2003;4:125-31.

4. Dai W, Yu S, Liang J, Zhang M. Nummular headache: Peripheral or central? One case with reappearance of nummular headache after focal scalp was removed, and literature review. Cephalalgia 2013;33:390-7.

5. Mulero P, Matarazzo M, Pedraza MI, et al. Nummular headache related to exercise or Valsalva maneuver. Clinical characteristics of 3 cases. Headache 2013;53:1167-8. 


\section{Barón et al}

6. Robbins M, Grosberg B. Menstrual-related numular headache. Cephalalgia 2010;30:507-8.

7. Cuadrado ML, Valle B, Fernández de las Peñas C, et al. Pressure pain sensitivity of the scalp in patients with nummular headache: A cartographic study. Cephalalgia 2010;30:200-6.

8. Fernández-de-las-Peñas C, Madeleine P, Cuadrado ML, Ge HY, Arendt-Nielsen L, Pareja JA. Pressure pain sensitivity mapping of the temporalis muscle revealed bilateral pressure hyperalgesia in patients with strictly unilateral migraine. Cephalalgia 2009;29:670-6.

9. Guerrero AL, Cortijo E, Herrero-Velázquez S, et al. Nummular headache with and without exacerbations: Comparative characteristics in a series of 72 patients. Cephalalgia 2012;32:649-53.
10. Moon J, Ahmed K, Garza I. Case series of sixteen patients with nummular headache. Cephalalgia 2010;30:1527-30.

11. Ruscheweyh R, Buchheister A, Gregor N, Jung A, Evers S.

Nummular headache: Six new cases and lancinating pain attacks as possible manifestation. Cephalalgia 2010;30:249-53.

12. Kelman L. Migraine pain location: A tertiary care study of 1283 migraineurs. Headache 2005;45:1038-47.

13. Alvarez M, Montojo T, de la Casa B, Vela L, Pareja JA. Unilateral nasal pain with migraine features. Cephalalgia 2013;33:1055-8. 


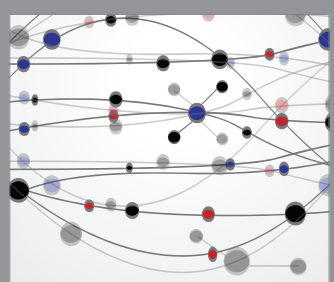

The Scientific World Journal
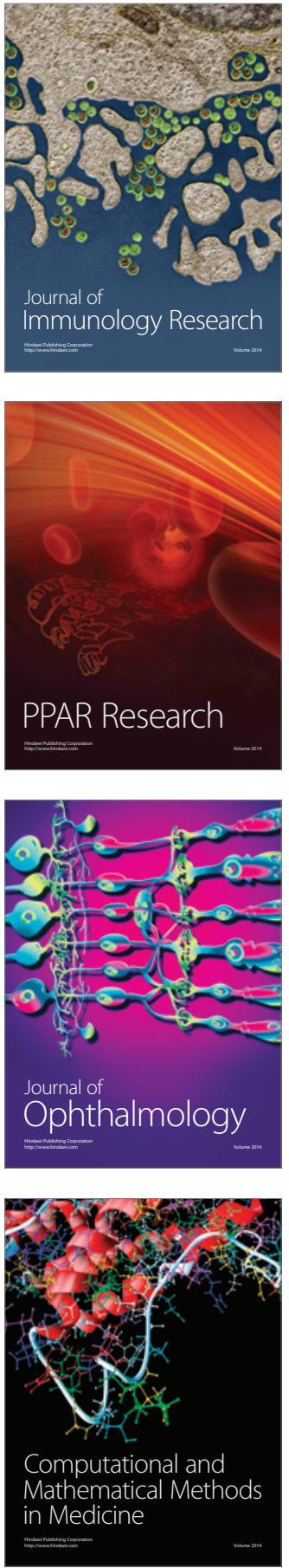

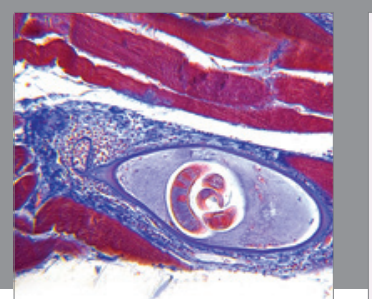

Gastroenterology Research and Practice

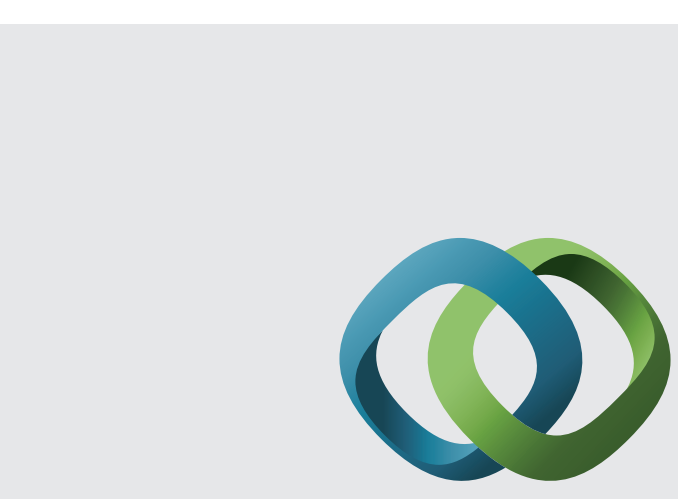

\section{Hindawi}

Submit your manuscripts at

http://www.hindawi.com
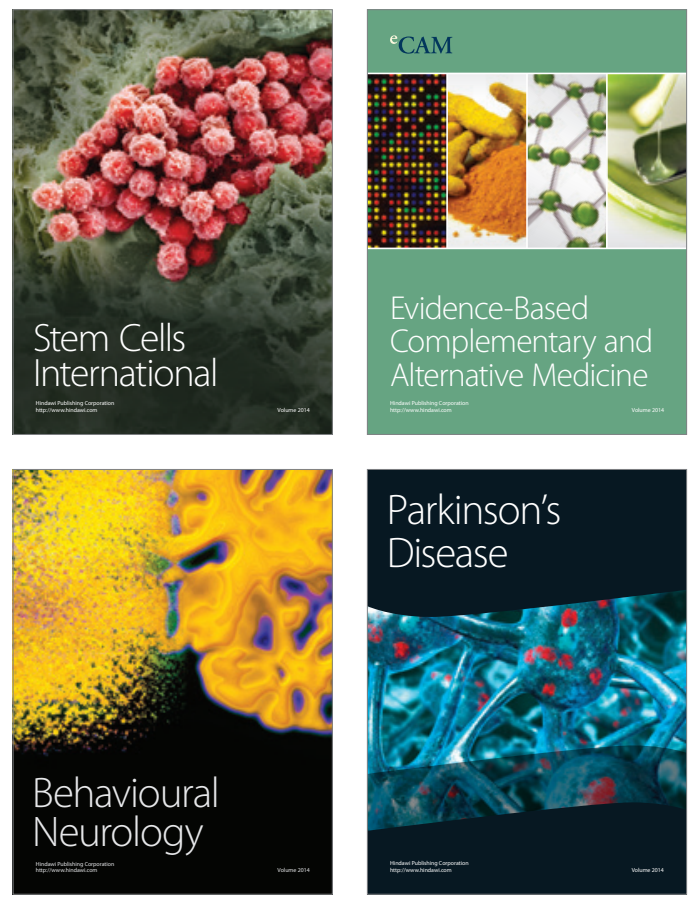
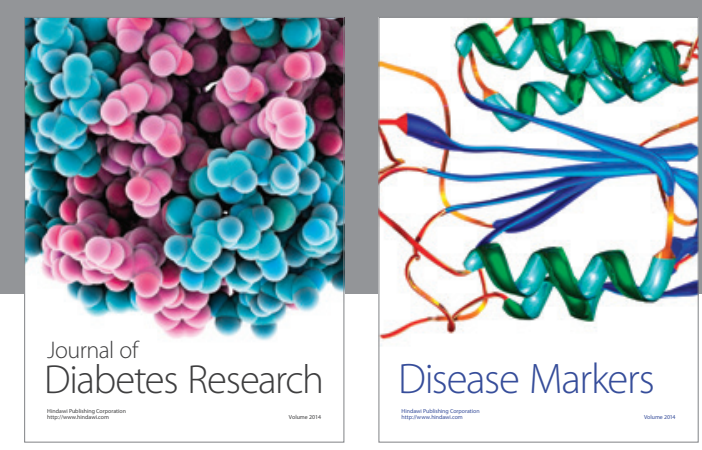

Disease Markers
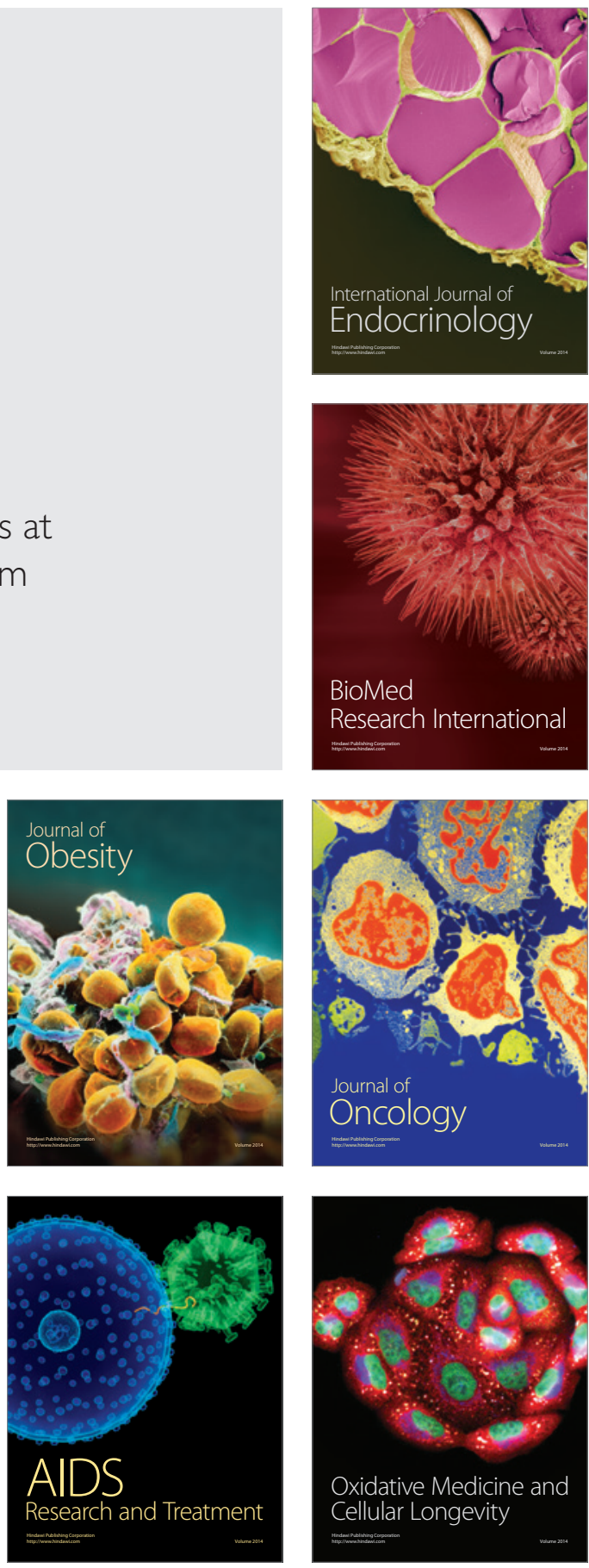